This is the accepted version of the article:

Fernandez-Regu Lez M., Solano E., Evangelio L., Gottlieb S., Pinto-Gomez C., Rius G., Fraxedas J., Gutierrez-Fernandez E., Nogales A., Garcia-Gutierrez M.C., Ezquerra T.A.,

Perez-Murano F.. Self-assembly of block copolymers under nonisothermal annealing conditions as revealed by grazing-incidence small-angle X-ray scattering. J ournal of Synchrotron Radiation, (2020). 27. : 1278 - . $10.1107 /$ S1600577520009820.

Available at: https://dx.doi.org/10.1107/S1600577520009820 


\title{
Self-assembly of block copolymers under non-isothermal annealing conditions as revealed by grazing-incidence small-angle $X$-ray scattering
}

Authors

\author{
Marta Fernández-Regúlez ${ }^{\text {ab }}$, Eduardo Solano ${ }^{\mathrm{c}}$, Laura Evangelio ${ }^{\text {ad }}$, Steven Gottlieb ${ }^{\mathrm{a}}$, Christian

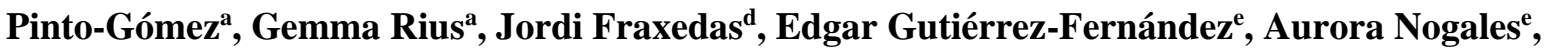

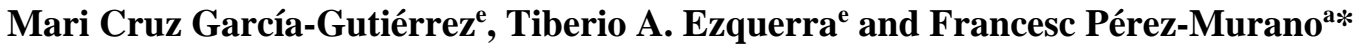 \\ a Instituto de Microelectrónica de Barcelona, IMB-CNM (CSIC), Campus UAB, Bellaterra, \\ Barcelona, 08193, Spain \\ ${ }^{\mathrm{b}}$ Universitat Autònoma de Barcelona, Bellaterra, 08193, Spain \\ 'NCD-SWEET beamline, ALBA synchrotron light source, Cerdanyola del Vallès, Barcelona, 08290, \\ Spain \\ ${ }^{\mathrm{d}}$ Catalan Institute of Nanoscience and Nanotechnology (ICN2), CSIC and BIST, Bellaterra, 08193, \\ Spain \\ e Instituto de Estructura de la Materia (IEM-CSIC), Serrano 121, Madrid, 28006, Spain
}

Correspondence email: francesc.perez@csic.es

Synopsis The self-assembly kinetics of a lamellar block copolymer is accurately characterized in situ and at real time using GISAXS. A novel modelling methodology is implemented for the determination of self-assembly kinetic parameters by properly considering the initial annealing conditions for both isothermal and non-isothermal processes.

Abstract An accurate knowledge of the parameters governing the kinetics of block copolymer self-assembly is crucial to model the time and temperature dependent evolution of pattern formation during annealing as well as to predict the most efficient conditions for the formation of defect-free patterns. Here, the self-assembly kinetics of a lamellar PS-b-PMMA block copolymer under both isothermal and non-isothermal annealing conditions is investigated by combining Grazing-Incidence Small-Angle X-ray Scattering (GISAXS) experiments with a novel modelling methodology that accounts for the annealing history of the block copolymer film before reaching its isothermal regime. Such model allows to extend the conventional studies in isothermal annealing conditions to the more realistic case of non-isothermal annealing and to predict the accuracy in the determination of the 
relevant parameters, namely the correlation length and the growth exponent, which define the kinetics of the self-assembly.

\section{Keywords: Block copolymer; self-assembly; kinetics; correlation length; GISAXS.}

\section{Introduction}

The self-assembly of block copolymer (BCP) thin films has gained interest during the last decade due to its application as a complementary process for nanostructuring surfaces.(Jeong et al., 2013; Bates et al., 2014) Particularly, BCP-based large-area patterning can reliably achieve sub-20 nm resolution at low cost and with process simplicity. Pursuing its ultimate development in terms of resolution, defectivity and process integration would allow its implementation in the next technological nodes.

BCPs are composed of two (or more) homopolymer chains, whose blocks are chemically distinct while linked through a covalent bond.(Bates, 1990) When the repulsive interaction between blocks is high enough, a phase separation can be induced by thermal or solvent annealing.(Jung \& Ross, 2009) Different structural nanodomains, such as lamellas, cylinders or spheres, can be obtained depending on the degree of interaction among the polymer chains, which is quantified by the Flory Huggins interaction parameter, $\chi$, plus the number of monomers, $\mathrm{N}$, and the volume fraction of each block, $\mathrm{f}$. However, self-assembled nanopatterns usually present a random orientation and short order domains. To overcome this limitation, directed self-assembly (DSA) combines standard lithography techniques to create topographical (graphoepitaxy(Gottlieb, Kazazis et al., 2018)) or chemical (chemoepitaxy(Fernandez-Regulez et al., 2014; Evangelio et al., 2019)) guiding patterns, so that specific orientation and position of the block copolymer self-assembled structures can be obtained.(Hu et al., 2014) DSA of BCPs is still considered by the semiconductor industry as a complementary approach to conventional photolithography and patterning towards improving parameters such as resolution, throughput or line edge roughness.(IRDS, 2018) Nevertheless, its incorporation in fabrication processes requires the consolidation of multiple parameters such as defectivity, compatibility of self-assembly process conditions, kinetics and throughput among others.(Marencic \& Register, 2010; Tseng \& Darling, 2010; Li \& Müller, 2016)

The understanding of the parameters governing the kinetics of BCP self-assembly process is of key importance to model the evolution of the system as it can be crucial to predict the final order and determine the processing conditions to obtain defect-free patterned areas (Harrison et al., 2002; Murphy et al., 2015; Kim et al., 2014). Both, the self-assembly kinetics and obtained morphology, have been widely investigated as a function of different physical/experimental parameters (Ji et al., 2011) such as annealing conditions, (Berry et al., 2007; Sanz et al., 2011; Majewski \& Yager, 2015; Gu et al., 2014) BCP thickness(Black et al., 2017) and BCP/substrate interaction.(Harrison, Chaikin et al., 2000) Typically, the characterization of BCP thin films is addressed by using microscopy techniques. In particular, scanning electron microscopy (SEM),(Harrison et al., 2004; Ferrarese Lupi 
et al., 2013; Perego et al., 2014) atomic force microscopy (AFM) (Magerle, 2000; Hahm \& Sibener, 2001; Berry et al., 2007; Chandra et al., 2019) or transmission electron microscopy (TEM) (SegalPeretz et al., 2015) have been extensively used. However, despite their high spatial resolution, they only inform about the material surface, like in the case of SEM and AFM, and they are typically limited to surveying small areas. Therefore, conventional topographical characterization of selfassembled BCP layers taken at different sample positions offers limited possibility for statistical analysis of pattern quality and defectivity, and its evaluation is time consuming. Moreover, in situ and real time characterization of the time evolution of the system is limited because of the time resolution inherent to microscopy methods and the incompatibility of equipment with the required harsh conditions involved in the sample processing. In this scenario, Grazing-Incidence Small-Angle X-ray Scattering (GISAXS) with synchrotron radiation plays a pivotal role to complement the evaluation provided by standard microscopy techniques, (Müller-Buschbaum, 2016; Soccio et al., 2014; Rueda et al., 2012; Gottlieb, Rösner et al., 2018) due to the fact that GISAXS probes a sample area that can be several orders of magnitude larger, typically square millimeters, than the one explored by microscopy techniques, thanks to the glancing X-ray beam and hence large footprint.. Moreover, the collected information is not limited to the polymer surface (Ferrarese Lupi et al., 2017) but also includes certain sample volume because of the X-ray penetration into the material, which can be controlled by the incidence angle. This feature opens the possibility for statistical analysis of large areas while having access to information from the entire depth of the film.(Müller-Buschbaum, 2016) In addition, GISAXS set-ups often allow the experiments to be performed in a wide range of sample environments and configurations, e.g. high temperature, vacuum, controlled atmosphere conditions, etc., making possible to perform in situ and real-time experiments such as solvent and thermal annealing of block copolymers.

Remarkably, due to the recent progress in synchrotron instrumentation for GISAXS, sub-millisecond time-resolution measurements can be performed, thus, enabling an accurate study of the kinetics of block copolymer self-assembly process. However, most of the reported in situ and real-time studies using synchrotron radiation were performed on solvent-annealed samples.(Papadakis et al., 2008; Di et al., 2010; Gu et al., 2014; Zhang et al., 2014; Sinturel et al., 2014; Berezkin et al., 2018; Lee et al., 2019) In general, the characterization of thermally annealed samples is mainly performed on already self-assembled ex situ samples by taking snapshots during the process of interest,(Ferrarese Lupi $e t$ al., 2017) while only few studies have been performed during the thermal annealing.(Yager et al., 2009; Sepe et al., 2011; Maret et al., 2014; Samant et al., 2016)

In this paper, we report on the self-assembly process of lamellar block copolymer poly (styrene-blockmethylmetacrylate), PS- $b$-PMMA thin films. The spin-coated/deposited block copolymer thin films were investigated by means of synchrotron GISAXS during thermal annealing (i.e. in situ) which consisted on either isothermal or non-isothermal conditions , and in particular during heating ramps at 
different heating rates. Real-time monitoring has allowed us to investigate the evolution of the pitch as well as the block copolymer correlation length, thus making possible to determine basic kinetics mechanism of the self-assembly process for the complete set of investigated samples. In fact, different from classical modeling, normally limited to isothermal annealing, our study has been extended to and provides predictions for systems with diverse initial sample conditions including: i) unknown previous annealing history and ii) pre-annealing evaporation of the solvent at low temperature. In addition, dedicated data analysis enables us to predict the evolution of the system under arbitrary nonisothermal annealing conditions. The model successfully predicts the evolution of the correlation length during the heating ramp. When the final target temperature has been reached after the heating ramp, the evolution during the isothermal annealing is modelled considering the previous evolution of the self-assembly.

\section{Experimental Section}

\subsection{Materials and sample preparation}

Lamellar PS- $b$-PMMA (50:50, molecular weight $\mathrm{M}_{\mathrm{n}}=79 \mathrm{~kg} \mathrm{~mol}^{-1}$ and PDI = 1.09) block copolymer and its associated neutral layer (same wetting affinity for both BCP blocks) PS- $r$-PMMA (molecular weight $7.9 \mathrm{~kg} \mathrm{~mol}^{-1}, 58 \mathrm{wt} \%$ PS and 42\% PMMA and PDI =1.85) were provided by Arkema. Both polymers were dissolved in propylene glycol monomethyl ether acetate (PGMEA) solvent at $1.5 \%$ in weight.

Samples were prepared on $2 \times 2 \mathrm{~cm}^{2}$ substrates from silicon wafers (p-type doped, <100> oriented and 4-40 $\Omega \mathrm{cm}^{-1}$ ). First, the substrates were conditioned by exposure to an oxygen plasma at $500 \mathrm{~W}$ for 10 min. Then, a thin layer of PS-r-PMMA was spin-coated (2000 rpm for 30s) on the surface and annealed at $230{ }^{\circ} \mathrm{C}$ in air for $10 \mathrm{~min}$ for grafting. The un-grafted polymer chains were removed by dipping the sample on an ultrasonic bath with PGMEA solvent for $1 \mathrm{~min}$. Finally, the block copolymer, PS- $b$-PMMA, was spin-coated at $2500 \mathrm{rpm}$ and immediately placed on the GISAXS sample holder to perform its in situ thermal annealing characterization to monitor the self-assembly process. Due to the employed annealing conditions and the surface brush functionalization, perpendicular oriented lamellar structures with a period of $38 \mathrm{~nm}$ were formed.(Gottlieb et al., 2017; Lorenzoni et al., 2017)

\subsection{Sample characterization}

In situ GISAXS measurements were carried out at the NCD-SWEET beamline at ALBA synchrotron (Cerdanyola del Vallès, Spain) during two separate campaigns/sets of experiments. An X-ray beam of $12.4 \mathrm{keV}$ was set using a $\mathrm{Si}$ (111) channel cut monochromator. Then, the beam was collimated using an array of Be lenses, obtaining a beam size of $475 \times 340 \mu \mathrm{m}^{2}(\mathrm{H} \times \mathrm{V})$ at the sample position. The scattered radiation was recorded with a Pilatus3 S 1M detector (Dectris ${ }^{\circledR}$, Switzerland), which 
consists of an array of $981 \times 1043(\mathrm{H} \times \mathrm{V})$ pixels of $172 \times 172 \mu \mathrm{m}^{2}(\mathrm{H} \times \mathrm{V})$. The sample to detector distance was $4046 \mathrm{~mm}$ for a first set, and $6036 \mathrm{~mm}$ for the second round of experiments. The sample to detector distance, as well as the reciprocal space, was calibrated using a silver behenate sample for calibration. The X-ray incident angle employed was $0.15^{\circ}$, which corresponds to the critical angle of the Si substrate for the set energy, ensuring minimum penetration and high surface sensitivity.

An adapted Linkam ${ }^{\circledR}$ TMS600 films heating stage (accuracy $0.01{ }^{\circ} \mathrm{C}$ ) for grazing-incidence experiments was employed for the in situ annealing experiments. Sample temperature was corrected by a calibration curve previously obtained. A protective $\mathrm{N}_{2}$ atmosphere was used during the performed experiments. For the isothermal annealing, the samples were first placed at room temperature on the heating stage and then heated-up to the target annealing temperature (between 160 ${ }^{\circ} \mathrm{C}$ and $200{ }^{\circ} \mathrm{C}$ ) using a heating ramp of up to $50{ }^{\circ} \mathrm{C} / \mathrm{min}$ without being exposed to X-rays. GISAXS patterns during the isothermal experiments were collected at the (final) target temperature. On the other hand, samples for the study of non-isothermal treatments were annealed from room temperature to $180{ }^{\circ} \mathrm{C}$ using different heating rates $\left(5,10\right.$ and $20{ }^{\circ} \mathrm{C} / \mathrm{min}$ ), followed by a dwell time at the maximum temperature for $10 \mathrm{~min}$. In this case, GISAXS patterns were periodically taken during both transient phases, the heating ramp, and the steady phase, i.e. the isothermal annealing.

\subsection{GISAXS Analysis}

Prior to the in situ experiments, the radiation damage induced by the beam on the BCPs was evaluated at different temperatures (see supporting information Figure S1). We determined that a total sample exposure to the X-rays higher than $1.2 \mathrm{~s}$ induced significant damage to the sample, especially at temperatures above the polymer glass transition. Therefore, the GISAXS pattern acquisition time was limited to 30 frames per sample with an integration time of $37 \mathrm{~ms}$, limiting the sample beam-damage while obtaining an adequate signal to noise ratio for the recorded GISAXS 2D patterns. To guarantee experimental reproducibility, each experiment was repeated at least three times.

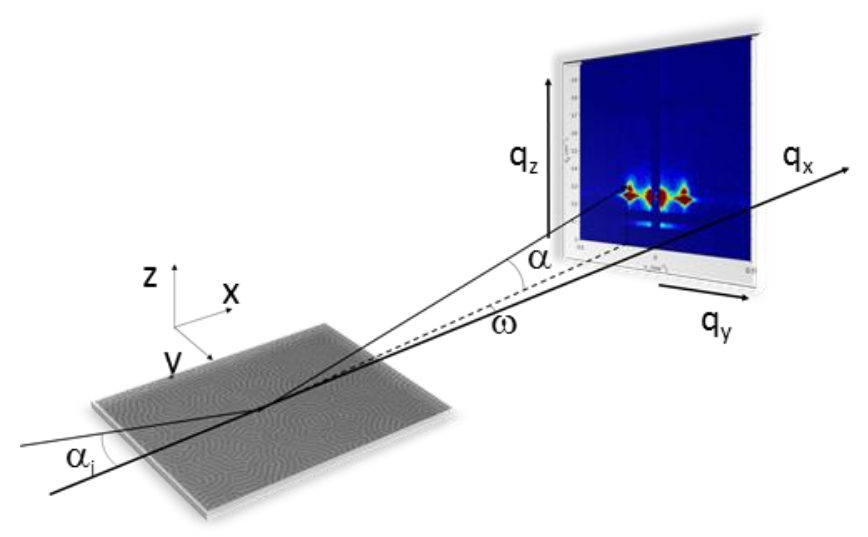


Figure 1 (a) SEM image of a PS-b-PMMA BCP sample, proving in real space the lamellar structure of the BCP sample. (b) Schematic representation of the GISAXS geometry: A monochromatic X-ray beam hits the sample with an incident angle $\alpha_{\mathrm{i}}$. The scattered radiation is recorded with an area 2D detector with respect to the $\alpha$ (out of plane) and $\omega$ (in plane) exiting angles. The reciprocal space units (q) represent the scattering wavevector, which depends on the X-ray energy $(\lambda)$ and the exiting angles $(\alpha$ and $\omega)$.

Figure 1 presents a scheme of the geometrical configuration of the GISAXS experiments specifying all relevant dimensions. The scattering vector $(q)$ is defined as a function of the incident X-ray beam angle $\left(\alpha_{i}\right)$ and the out of plane $(\alpha)$ and in plane $(\omega)$ exit angles:

$$
\begin{aligned}
& q_{x}=k_{0}\left(\cos \omega \cos \alpha-\cos \alpha_{i}\right) \\
& q_{y}=k_{0}(\sin \omega \cos \alpha) \\
& q_{z}=k_{0}\left(\sin \alpha_{i}+\sin \alpha\right)
\end{aligned}
$$

where $k_{0}=2 \pi / \lambda$ is the wave vector of the incident X-ray beam of wavelength $\lambda$.(Renaud et al., 2009)
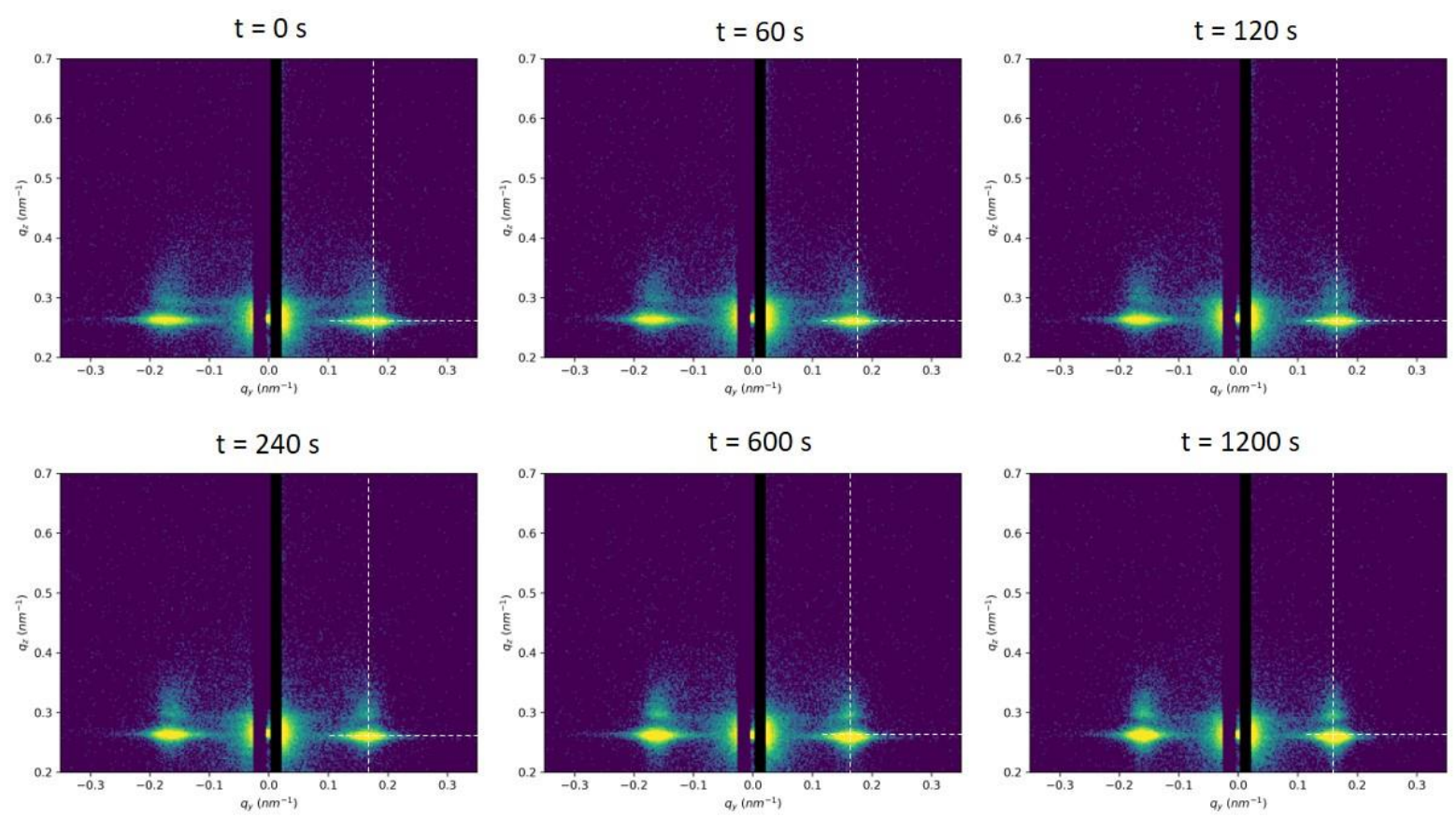

Figure 2 Selection of GISAXS patterns at different processing times during the thermal annealing at $180^{\circ} \mathrm{C}$. The dashed vertical and horizontal lines indicate the $\mathrm{q}_{\mathrm{y}}$ and $\mathrm{q}_{\mathrm{z}}$ main peak position for the further analysis using line cut profiles. After reaching $180^{\circ} \mathrm{C}(\mathrm{t}=0 \mathrm{~s})$ with a ramp rate of $50{ }^{\circ} \mathrm{C} / \mathrm{min}$, GISAXS patterns were collected with a frame rate of 1 frame of 37 ms every $60 \mathrm{~s}$. GISAXS patterns showed a clear scattering evolution of the block copolymer film during the isothermal process: lobe sharpness and the appearance of vertical second order peaks along $\mathrm{q}_{\mathrm{z}}$ were indicative of an increase of the long range structure of the $\mathrm{BCP}$. 
One example of the obtained 2D-GISAXS patterns during isothermal annealing is shown in Figure 2. Typically, the patterns exhibit a primary diffraction maximum at a certain position $\left(q_{y, p o s}, q_{z, p o s}\right)$ which is associated with the BCP period in perpendicularly-oriented lamellar structures $\left(\mathrm{L}_{0}\right)$. The recorded 2D-GISAXS patterns were analyzed by an in house-developed software based on MatLab®. 2D to 1D data reduction consisted of horizontal line cuts (along $q_{y}$ ) at the position of the main diffraction maximum $\left(q_{z, p o s}\right.$, ca. $\left.0.251 \mathrm{~nm}^{-1}\right)$, by means of integrating the number of pixels corresponding to a $\mathrm{q}$ interval of $q_{z, p o s} \pm 0.01 \mathrm{~nm}^{-1}$. The main peak $q_{y}$ position $\left(q_{y, p o s}\right)$ can be directly related with the average center-to-center distances between neighboring domains, while the peak width is inversely proportional to the correlation length defined as the domain long range order distance.(Förster et al., 2005) In fact, the period of the lamellar structures, $L_{0}$, from the $q_{y, p o s}$ can be calculated from the position of the scattering maximum as follows:

$$
L_{0}=\frac{2 \pi m}{q_{y, p o s}}
$$

where $\mathrm{m}$ is the order of the reflection (being $\mathrm{m}=1$ for the first scattering peak). The scattering peak $\mathrm{q}_{\mathrm{y}}$ maximum position was ca. $0.165 \mathrm{~nm}^{-1}$ which fits with the expected value for a polymer with $38 \mathrm{~nm}$ pitch. On the other hand, the grain size (i.e. the order of structure) is inversely proportional to the width of the scattering peak in GISAXS patterns. As the order in the perpendicularly-oriented lamellar structures of the block copolymer film increases, a narrowing of the first order Bragg peak occurs, concurrent with the eventual appearance of higher order peaks. The correlation length of selfassembled block copolymer can be related to the width of the first order scattering peak as follows:

$$
\xi=\frac{2 \pi k}{f w h m}
$$

where " $F W H M$ " is the full width half-maximum of the peak and $k$ is a correction parameter related to the detector type and the fitting of the peak (see Figure 3). For a 2D detector and a Gaussian fitting, $\mathrm{k}$ has been defined as 0.96.(Smilgies, 2009) In this work, the horizontal cuts in a window of $q_{y, p o s} \pm 0.15$ $\mathrm{nm}^{-1}$ were fitted to a Gaussian curve using a Matlab® code prior to the extraction of both the main peak position and FWHM. 


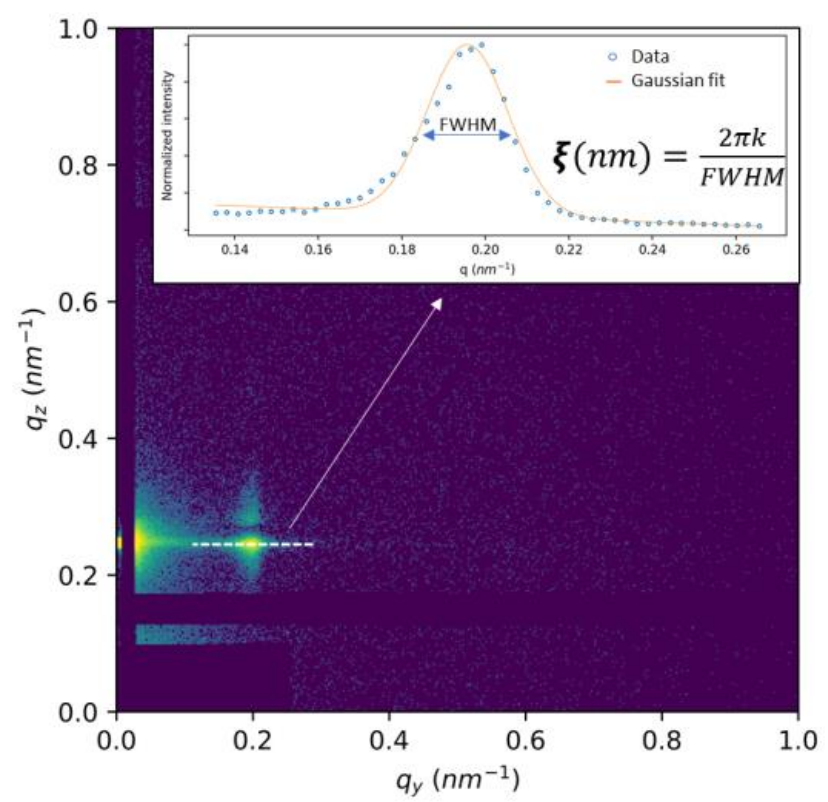

Figure 3 Calculation of the block copolymer correlation length using a Gaussian fit of the first order scattering peak.

\section{Experimental results and discussion}

\subsection{Isothermal annealing of block copolymers}

The evolution of the correlation length of BCPs as a function of time under isothermal annealing conditions follows the power law expression:(Harrison et al., 2004; Harrison, Adamson et al., 2000)

$$
\xi=A_{T} t^{\phi}
$$

where the growth exponent value, $\phi$, depends on the polymer material composition as well as the applied annealing conditions. It has a typical value of 0.1-0.3. The parameter $A_{T}$ depends on the temperature through an Arrhenius behaviour, which can be expressed as $A_{T}=A_{0} e^{-E_{A} / R T}$, where $E_{A}$ is an activation energy for the self-assembly which depends on the block co-polymer (composition, molecular weight and morphology).

However, equation (4) can be only applied when the self-assembly is strictly occurring at pure isothermal annealing process or when the target isothermal temperature is reached under rapid annealing conditions, i.e., when a negligible evolution of the self-assembly occurs during the short time required for reaching the isothermal temperature. Quantitatively, Perego and co-workers estimated that, in order to assume a rapid thermal annealing (RTA), a heating ramp faster than $18{ }^{\circ} \mathrm{C} / \mathrm{s}$ is needed.(Ferrarese Lupi et al., 2013) Moreover, it has been demonstrated that the final selfassembled film structure of a block copolymer film is affected both by the presence of intermediate states and by the heating rate (Majewski \& Yager, 2015). Therefore, the power law dependence for 
BCP self-assembly in equation (4) is not strictly valid under arbitrary annealing conditions and hence, a correction factor is required to obtain a precise modelling of the self-assembly evolution.

In fact, the isothermal experiments reported in this work show some polymer ordering occurring during the heating time involved in reaching the annealing temperature. Once isothermal temperature is reached, the BCP correlation length, $\left(\xi_{0}\right)$, is expected to depend on the previous history of the film (heating rate to reach the target temperature, solvent evaporation kinetics, etc.). In order to include the initial conditions into expression (4), an equivalent time, $\left(t_{e q}\right)$ has to be introduced as an offset, which corresponds to the time that the polymer would need to reach the initial observed correlation length under a purely isothermal annealing regime: $\xi_{0}=A_{T} t_{e q}^{\phi}$. Accordingly, equation (4) can be rewritten as:

$$
\xi=A_{T}\left(t+t_{e q}\right)^{\phi}
$$

Then, self-assembly kinetics of BCP during thermal annealing depends on three parameters: the growth exponent $(\phi)$, the Arrhenius coefficient $A_{T}$ and the equivalent time $\left(t_{e q}\right)$, which is directly related with the initial correlation length $\left(\xi_{0}\right)$ as $t_{e q}=\left(\frac{\xi_{0}(t=0)}{A_{T}}\right)^{\frac{1}{\phi}}$. A similar approach is used to model the kinetics of the silicon oxide thermal growth (Deal and Grove model) where the time coordinate is used to account for the presence of an initial oxide layer on the sample.(Deal \& Grove, 1965)

The analysis of the self-assembly process under isothermal annealing was performed at temperatures between $160{ }^{\circ} \mathrm{C}$ and $190{ }^{\circ} \mathrm{C}$, using a heating rate of $50{ }^{\circ} \mathrm{C} / \mathrm{min}$, well below the minimum value for being considered RTA. For annealing temperatures lower than $160{ }^{\circ} \mathrm{C}$, the block copolymer selfassembly kinetics is too slow to be efficiently monitored in situ by synchrotron experiments, since several hours are needed to observe some polymer order. On the contrary, at high annealing temperatures $\left(>190^{\circ} \mathrm{C}\right)$ the self-assembly kinetics is fast enough to produce the complete polymer ordering during the heating ramp. Thus, no significant changes were observed in the correlation length during the isothermal annealing from $200{ }^{\circ} \mathrm{C}$ and above.

During the isothermal annealing, GISAXS patterns correspond to snapshots of the structure and ordering of the block copolymer. Figure 2 presents a selection of 2D GISAXS patterns recorded during isothermal annealing at $180{ }^{\circ} \mathrm{C}$. GISAXS patterns during isothermal annealing at 160, 170 and $190^{\circ} \mathrm{C}$ can be found at supporting document Figure S2 to S4). It can be observed, first, the formation and, then, the evolution of scattering rods at ca. $\mathrm{q}_{\mathrm{y}}=0.165 \mathrm{~nm}^{-1}$ produced by the arrangement of lamellae perpendicular to the sample. From the recorded patterns, the correlation length evolution could be extracted. Figure 4 depicts the evolution of the $\mathrm{q}_{\mathrm{y}}$ horizontal cuts at the Yoneda peak position $\left(\mathrm{q}_{\mathrm{z}, \mathrm{pos}}\right)$ versus the annealing time for different temperatures. A detailed view of the evolution of the main scattering peak profiles with annealing time is shown in supporting information document, in 
Figure S5. As observed, the main scattering peak evolves by increasing its intensity and slightly shifting towards lower qy values. This characteristic evolution signals an increment of the scattering domain size, indicated by the narrowing of the scattering peak as well as an improved lamella packing, by the reduction of the $\mathrm{q}_{\mathrm{y}}$ peak position. As mentioned, to corroborate these findings, the same experiment was repeated several times for each isothermal target temperature $\left(160{ }^{\circ} \mathrm{C}, 170{ }^{\circ} \mathrm{C}\right.$, $180^{\circ} \mathrm{C}$ and $190^{\circ} \mathrm{C}$ ), see Figure 5. An additional experiment was performed by directly placing the sample on the heating stage to produce fast heating for thermal annealing, where the equivalent time would be zero $\left(t_{e q} \cong 0\right)$.
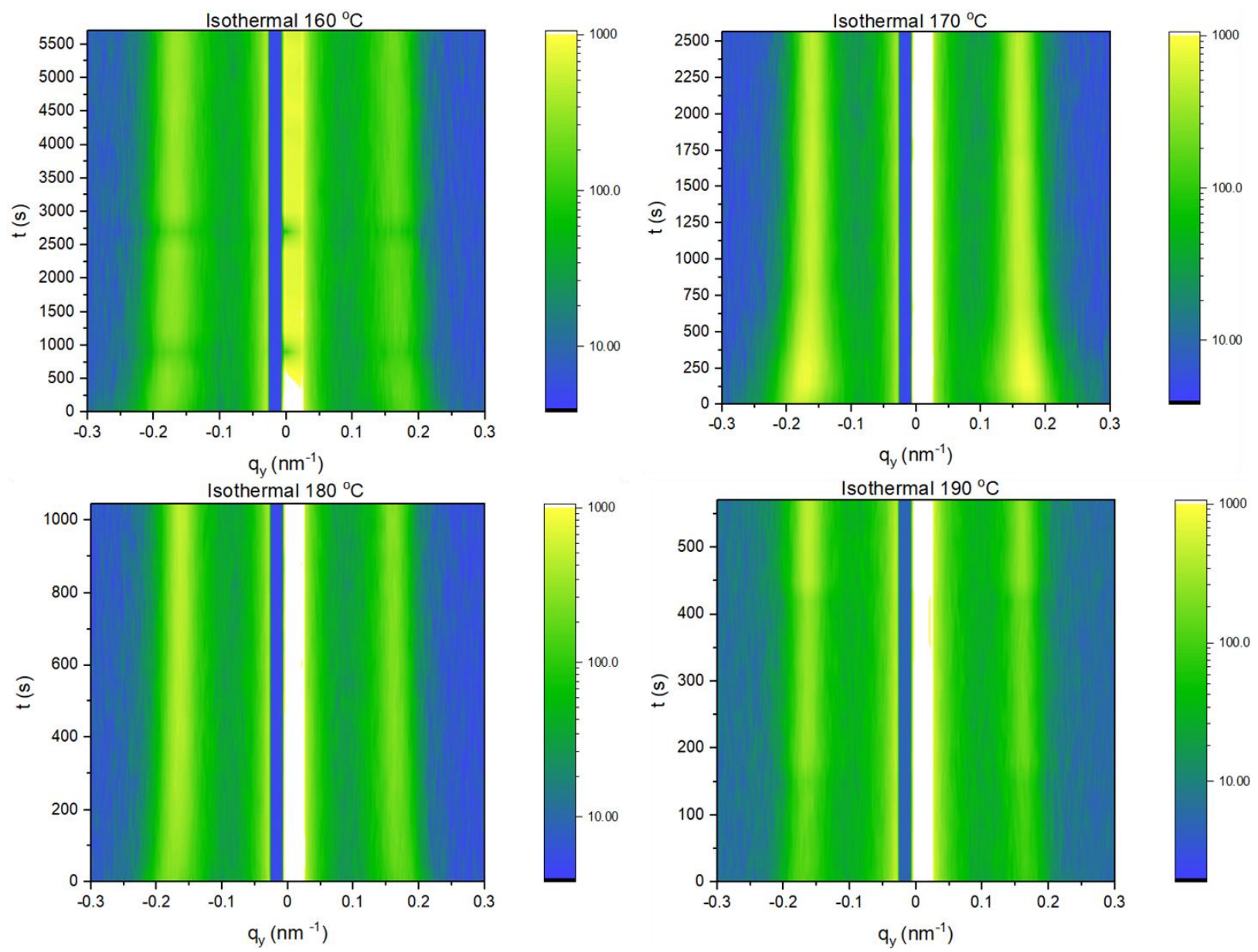

Figure 4 Dynamic evolution of the horizontal line profiles along $\mathrm{q}_{\mathrm{y}}$ at the Yoneda peak position during isothermal annealing at different temperatures $\left(160,170,180\right.$ and $\left.190^{\circ} \mathrm{C}\right)$. The color maps correspond to the intensity of the complete line profile taken at the Yoneda peak $\mathrm{q}_{\mathrm{z}}$ position, where the formation and shift towards lower $q_{y}$ values of the first order scattering peak was observed. 
Isothermal annealing experiments with slow heating rates resulted on a correlation length evolution following the canonical power law (equation (5)). Table 1 compiles the experimental $A_{T}$ and $\phi$ values extracted from the in situ data recorded during the annealing experiments. The extracted values (Table 2) were consistent with previously reported investigations for this polymer using SEM defectivity analysis at Claveau's thesis (Claveau, 2018) and for similar polymers.(Ji et al., 2011; Majewski \& Yager, 2015; Black et al., 2017) As expected, $A_{T}$ value increases following an Arrhenius behaviour, being the activation energy of the polymer $29.7 \mathrm{~kJ} / \mathrm{mol}$. Additionally, the $\phi$ values are within the ra

nge of previously reported values (Black et al., 2017; Perego et al., 2014; Majewski \& Yager, 2015; Ferrarese Lupi et al., 2017). It is worth mentioning the existence of a temperature dependence revealed by our experiments (Figure 6). This dependency can be well described by a linear law, according to the narrow range of temperatures under evaluation: $\phi(T)=\phi_{1}+\phi_{2} T$. The temperature dependence of $\mathrm{A}_{\mathrm{T}}$ and $\phi$ are shown in Figure 6 and the fitting parameters in Table 2. 
a)

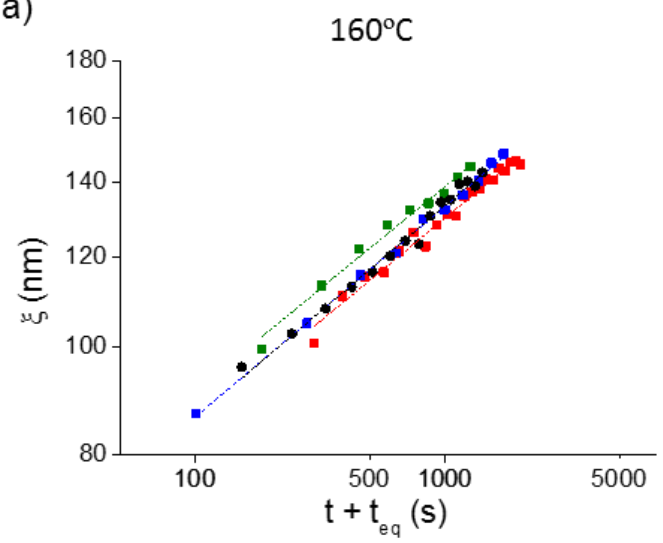

c)

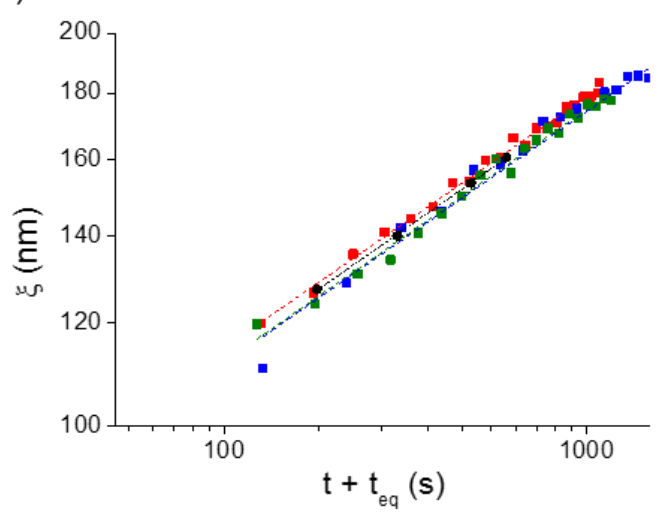

b)

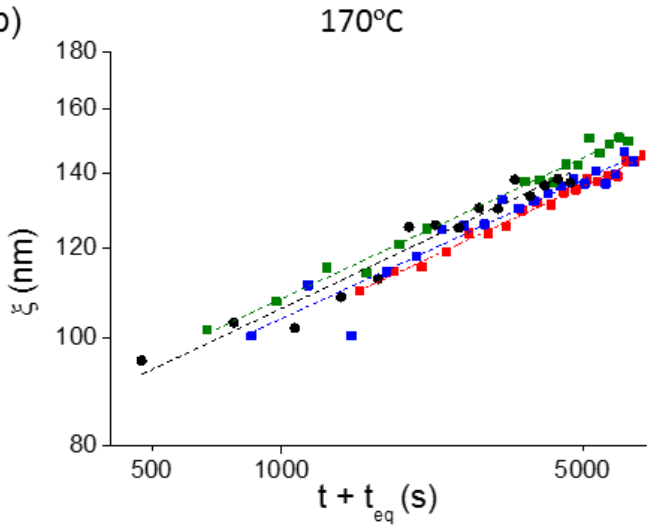

d)

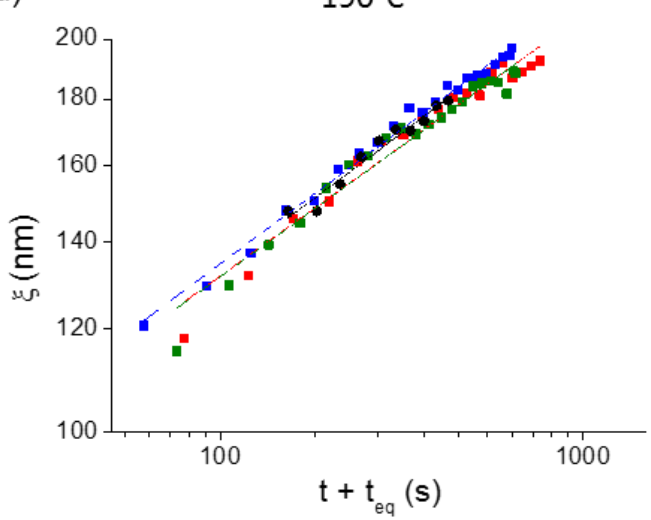

Figure 5 Correlation length evolution as a function of the annealing time at different isothermal treatments $\left(160^{\circ} \mathrm{C}, 170{ }^{\circ} \mathrm{C}, 180^{\circ} \mathrm{C}\right.$ and $\left.190^{\circ} \mathrm{C}\right)$. Four experiments were performed per each annealing treatment. On the first three experiments (represented by red, blue and green dots) the samples were annealed until the target temperature using a heating ramp of $50^{\circ} \mathrm{C} / \mathrm{min}$ while the fourth sample was directly placed on the hot plate at the annealing temperature (represented by black dots).

Table 1 Experimental fitting values of block copolymer kinetic parameters and relative errors

\begin{tabular}{lllll}
\hline $\mathrm{T} /{ }^{\circ} \mathrm{C}$ & $\phi$ & Error $\phi$ & $\mathrm{A}_{\mathrm{T}}(\mathrm{nm})$ & Error $\mathrm{A}_{\mathrm{T}}(\mathrm{nm})$ \\
160 & 0.1797 & 0.0084 & 30.40 & 2.09 \\
170 & 0.1894 & 0.0062 & 37.05 & 1.55 \\
180 & 0.1931 & 0.0030 & 46.46 & 0.94 \\
190 & 0.2033 & 0.0096 & 52.10 & 2.95 \\
\hline
\end{tabular}


a)

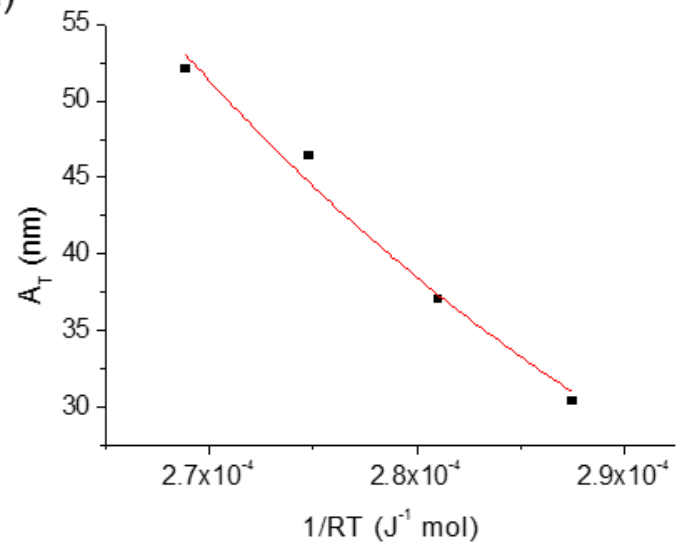

b)

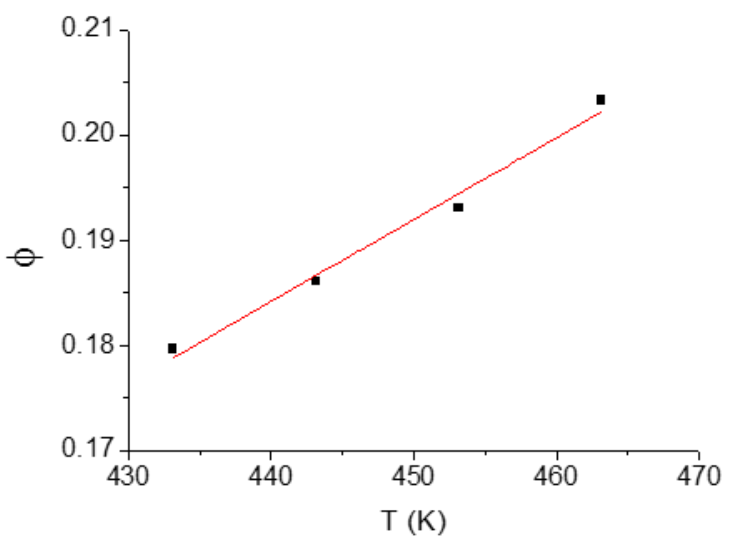

Figure 6 Block copolymer kinetic parameters dependence with temperature a) Arrhenius dependence of $\mathrm{A}_{\mathrm{T}}$ parameter evolution as a function of temperature b) Exponential parameter temperature dependence. As a first approach we have assumed a linear dependence with temperature $\left(\phi=\phi_{1}+\phi_{2} T\right)$

Table 2 Fitting values for temperature dependence of Arrhenius parameter, $A_{T}=A_{0} e^{-E_{a} / R T}$, and growth exponent $\phi=\phi_{1}+\phi_{2} T$

\begin{tabular}{llllll}
\hline & Value & Error & & Value & Error \\
$\mathrm{A}_{0}(\mathrm{~nm})$ & $1.253 \mathrm{E} 5$ & $9.32 \mathrm{E} 4$ & $\phi_{1}$ & -0.158 & 0.0285 \\
$\mathrm{E}_{\mathrm{A}}(\mathrm{kJ} / \mathrm{mol})$ & 29.7 & 2.3 & $\phi_{2}$ & $7.785 \mathrm{E}-4$ & $6.35 \mathrm{E}-5$
\end{tabular}




\subsection{Non-isothermal annealing of block copolymers}

The evolution of the block copolymer lamellar structure under non-isothermal annealing conditions has not been previously studied in as much detail as under isothermal annealing. The modeling of the self-assembly evolution becomes more complex due to the fact that BCP parameters $\left(A_{T}(T), \phi(T)\right)$ are changing during the self-assembly process. Consequently, for the block polymer under evaluation, we have extracted the dependence with temperature of both parameters from the isothermal experiments. Thus, we can model their time evolution for any arbitrary thermal treatment for which the temperature is known at each moment. We have implemented an extended model of the selfassembly evolution by dividing the self-assembly process into infinitesimal time intervals, $d t$, where we can assume that the self-assembly is evolving as under isothermal annealing. A new equivalent time is calculated for each new isothermal interval.

As example, we have evaluated the particular case of an annealing ramp with a constant heating rate, $r$, as it is depicted in Figure 7. Here, we have divided the annealing time in intervals with a length dt and we have recalculated the parameters, $\left(A_{T}(T), \phi(T), t_{e q}\right)$ per each time interval.

For the first time interval, as in previous isothermal studies, the equivalent time, $t_{e q 0}$, is the one corresponding to the experimental initial correlation length of the sample, $\xi_{0}$, at the initial temperature, $T_{1}$

$$
\begin{gathered}
\xi(\mathrm{t}=0)=\xi_{0}=A_{T}\left(T_{1}\right) t_{e q 0}\left(\phi_{1}+\phi_{2} T_{1}\right) \\
t_{e q 0}=\left(\frac{\xi_{0}(\mathrm{t}=0)}{A_{T}\left(T_{1}\right)}\right)^{1 /\left(\phi_{1}+\phi_{2} T_{0}\right)}
\end{gathered}
$$

Then, during the first time interval, $t \in(0, d t)$, the polymer correlation length evolves as:

$$
\xi_{1}(\mathrm{t})=A_{T}\left(T_{1}\right)\left(t+t_{e q 0}\right)^{\left(\phi_{1}+\phi_{2} T_{1}\right)}
$$

We can recalculate a new equivalent time, $t_{e q 1-2}$, at the end of the first time interval ( $\mathrm{t}=\mathrm{dt}$ ) for the evaluation of the polymer correlation length, $\xi_{2}$, under next isothermal temperature, $T_{2}=T_{1}+d T=$ $T_{1}+r d t$, during next period from $t \in(d t, 2 d t)$ by enforcing the continuity of $\xi(\mathrm{t})$ :

$$
\begin{gathered}
t_{e q 1-2}=\left(\frac{\xi_{1}(\mathrm{dt})}{A_{T}\left(T_{2}\right)}\right)^{1 /\left(\phi_{1}+\phi_{2} T_{2}\right)} \\
\xi_{2}(\mathrm{t})=A_{T}\left(T_{2}\right)\left(t+t_{e q 1-2}\right)^{\left(\phi_{1}+\phi_{2} T_{2}\right)}
\end{gathered}
$$

A straightforward recalculation of the modified correlation length and the corresponding equivalent time for each interval of time $\mathrm{n}$, under a new isothermal temperature $T_{n}=T_{1}+n r d t$ leads to:

$$
\xi_{n}(\mathrm{t})=A_{T}\left(T_{n}\right)\left(t+t_{e q(n-1)-n}\right)^{\left(\phi_{1}+\phi_{2}\left(T_{n}\right)\right)}
$$




$$
t_{e q(n-1)-n}=\left(\frac{\xi((\mathrm{n}-1) d t)}{A_{T}\left(T_{n}\right)}\right)^{1 /\left(\phi_{1}+\phi_{2} T_{n}\right)}
$$

Figure 7Error! Reference source not found. depicts graphically the result of consecutive application of equations (11) and (12): the mathematical modeling is equivalent to translate a segment of the isothermal curve (red, green and blue curves) a time equal to teq to fit to the value of the correlation length on the non-isothermal curve (pink curve) at the initial time of the interval $d t$. In the figure $d t$ is set to $10 \mathrm{~s}$ for clarity. When modelling real experiments at a constant heating rate, the interval of time, $d t$, is taken small enough to assume that during each time the system evolve under isothermal conditions, preventing the introduction of any significant error. For samples analyzed on this paper, the heating ramps is divided into 1000 isothermal steps, what corresponds to $d t$ values between 0.0025 $\mathrm{s}$ and $0.01 \mathrm{~s}$. Then, the time correlation length evolution is solved numerically using equations (6) to (10) by implementing a MATLAB routine.

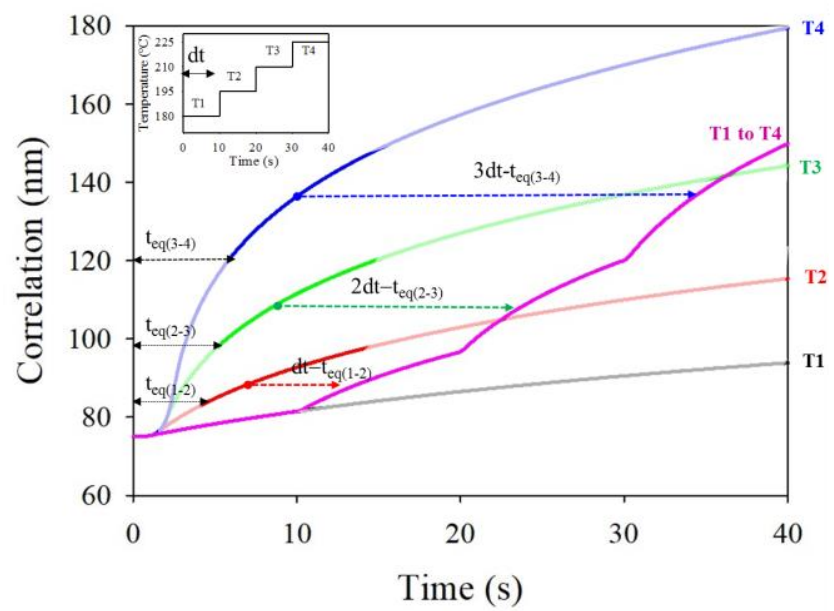

Figure 7 Modelling of the non-isothermal annealing. This figure illustrates the procedure to determine the evolution of the correlation length when the annealing temperature is not constant. To clarify the process, in this example the ramp temperature has a step like form with time steps of 10 seconds, as it is shown in the inset. The heating rate for the model is of $90^{\circ} \mathrm{C} / \mathrm{min}$ and the initial and final temperature is $180^{\circ} \mathrm{C}$ and $215^{\circ} \mathrm{C}$ respectively. At each step, the evolution follows that of an isothermal annealing but translated a certain time $\left(\mathrm{t}_{\mathrm{eq}}\right)$ to ensure the continuity of the actual correlation length.

The structural evolution of the BCP lamellar structure was obtained for different heating rates (5 ${ }^{\circ} \mathrm{C} / \mathrm{min}, 10^{\circ} \mathrm{C} / \mathrm{min}$ and $20^{\circ} \mathrm{C} / \mathrm{min}$ ). Samples were placed after the spin coating step at the heating stage and heated up to the target temperature of $180^{\circ} \mathrm{C}$. Then, after reaching the final temperature of $180{ }^{\circ} \mathrm{C}$, the polymer was annealed under isothermal conditions during few minutes. The initial temperature of the heating ramp for the studies was chosen to be $150{ }^{\circ} \mathrm{C}$ that is the temperature at which polymer evolution starts to be observed (see supporting document Figure S6).. At lower 
temperature, the evolution of the correlation length is difficult to evaluate due to low intensity and the width of the peaks which difficulties the Gaussian fit. The block copolymer kinetics is also very slow and the effect of the annealing in the block copolymer order is not observed at low temperatures (see Figure S6 at supporting document). Additionally, the initial order present on the samples at $150{ }^{\circ} \mathrm{C}$ can be mainly attributed to the evaporation of the remaining PGMEA solvent on the film, that take place during the spin-coating and the first minutes of the heating ramps. This effect is especially important in these experiments due to the slow heating rates used during the ramp.

Figure 8 shows the experimental correlation length versus the time at the final temperature obtained from the collected GISAXS patterns during the in situ characterization for non-isothermal experiments. Initial correlation lengths on samples at $\mathrm{t}=0\left(150^{\circ} \mathrm{C}\right)$ are different due to the previous thermal history of each sample. Samples were heated up from room temperature up to $150^{\circ} \mathrm{C}$ by using a ramp of 5,10 and $20^{\circ} \mathrm{C} / \mathrm{min}$ respectively. Then, sample with slower heating ramp has higher initial correlation length because of the longer thermal history.

It can be observed that low heating rates require higher time at the isothermal final temperature to achieve the final lamellar structure. These experimental data were compared with the predicted values using the proposed model (Figure 8). The results show that the model predicts satisfactorily the obtained experimental values for the three heating rates investigated. It is worthwhile to remark that there are not fitting parameters in the modelling: the values of $A_{T}$ and $\phi$ obtained from the isothermal characterization are considered.

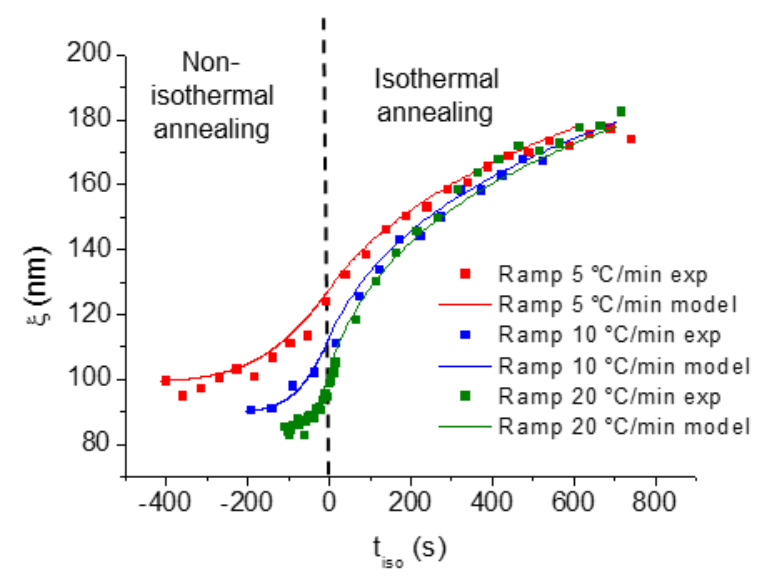

Figure 8 Correlation length time evolution during a heating ramp, at $5{ }^{\circ} \mathrm{C} / \mathrm{min}$ (red), $10^{\circ} \mathrm{C} / \mathrm{min}$ (blue) and $20^{\circ} \mathrm{C} / \mathrm{min}$ (green), from $150^{\circ} \mathrm{C}$ to $180^{\circ} \mathrm{C}$ followed by isothermal annealing at $180^{\circ} \mathrm{C}$. The time origin $(\mathrm{t}=0)$ is defined as the beginning of the isothermal annealing. Experimental values are represented by dots and the evolution predicted by the mathematical model (equations (11) and (12)) by lines.

After the mathematical model verification, we are able to predict how the annealing conditions, heating rate and initial correlation length influence the kinetics of the self-assembly process. Figure 9a 
and $\mathrm{c}$ illustrate the evolution of the correlation length during the thermal annealing at $1{ }^{\circ} \mathrm{C} / \mathrm{min}$ to 180 ${ }^{\circ} \mathrm{C}$ and $230{ }^{\circ} \mathrm{C}$, respectively, as a function of the initial polymer correlation length. Results show that for short isothermal annealing times, and especially at the lower temperatures $\left(180^{\circ} \mathrm{C}\right)$, there is a clear influence of the initial correlation length, indicating that the previous history of the polymer plays a role on the correlation length evolution. Complementarily, Figure $9 \mathrm{~b}$ and $\mathrm{d}$ present the evolution of the correlation length for different temperature ramp rates for a constant initial correlation length of $90 \mathrm{~nm}$. The model shows a clear dependence of the correlation length evolution with the final target temperature as well as with the heating rate employed. It is observed that a pure isothermal evolution (that would correspond to a constant slope in the figures, as they are represented in log-log form) is only obtained for a significant amount of time after the heating ramp has finished.

$\mathrm{T}=180^{\circ} \mathrm{C}$

a)

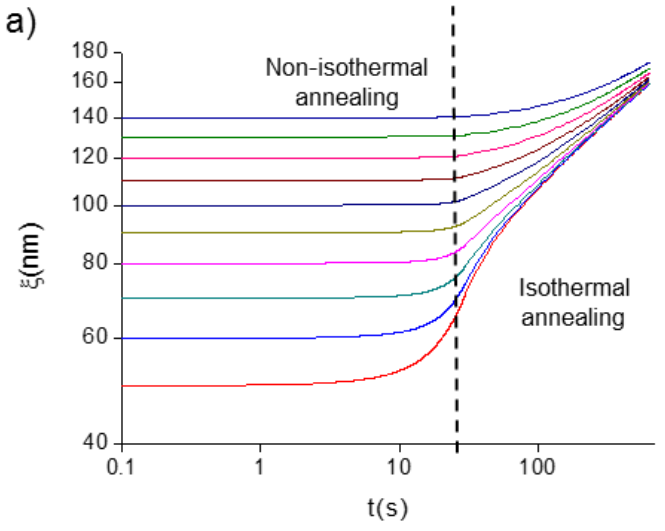

c)

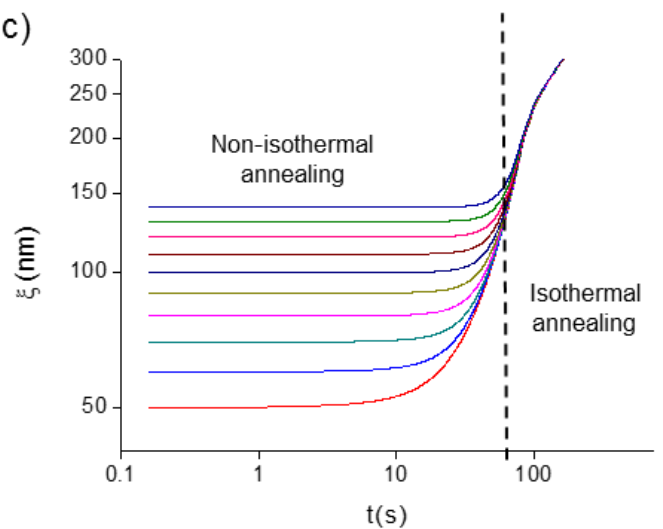

b)

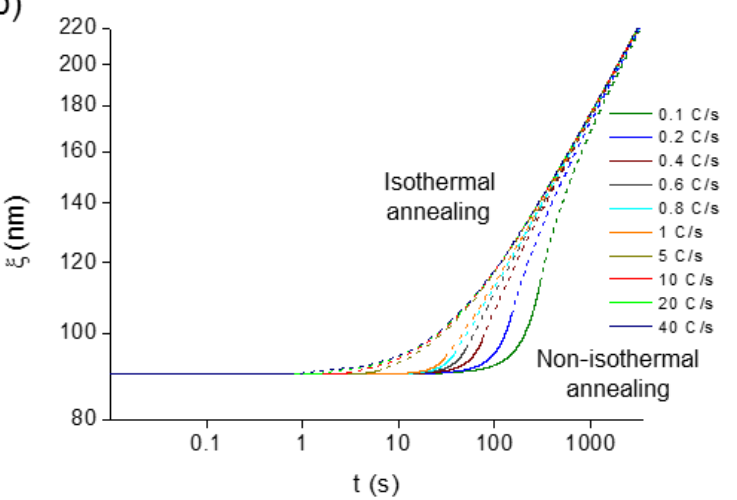

$\mathrm{T}=230^{\circ} \mathrm{C}$

d)

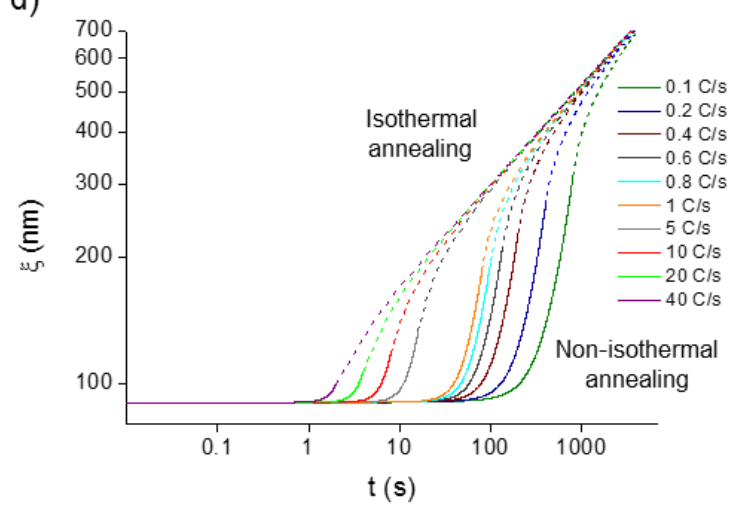

Figure 9 Modeling of correlation length evolution for a block copolymer from $150^{\circ} \mathrm{C}$ to the target temperature $180^{\circ} \mathrm{C}$ (top) and $230^{\circ} \mathrm{C}$ (bottom). The figures on the left (a and c) illustrate the influence of the initial correlation length. The annealing is performed first with a temperature ramp of $1{ }^{\circ} \mathrm{C} / \mathrm{s}$ and then isothermal annealing once the target temperature is reached, as indicated by the vertical line. For the figures on the right ( $b$ and d), the block copolymer film is annealed using different temperature ramp rates (from $0.1{ }^{\circ} \mathrm{C} / \mathrm{s}$ to $40^{\circ} \mathrm{C} / \mathrm{s}$ and then kept at constant temperature for few min). 
The initial correlation length is $90 \mathrm{~nm}$. All ramps are starting at $\mathrm{t}=0 \mathrm{~s}$. and correlation length during the ramp is represented by solid lines and dashed lines when isotherm is reached.

As a consequence the extraction of block copolymer kinetic parameters using the classic approach, $\xi=A_{T} t^{\phi}$, is only valid for a pure isothermal annealing, where the target temperature has been quasi instantaneously reached or using a fast thermal annealing. We have compared the calculation of $\phi$ using the classic approach (see supporting information Figure S7) with the accurate modelling that we have presented (Figure 10). When $\phi$ is estimated using the classical approach on samples previously annealed with a relatively slow heating rate, the obtained value is lower than the real one, and it is only reached after long annealing time. Consequently, in order to reach an accurate value of $\phi$ the experiment must consider a long enough annealing time under isothermal conditions. The minimum annealing time under isothermal conditions depends on the annealing temperature and on the heating rate.

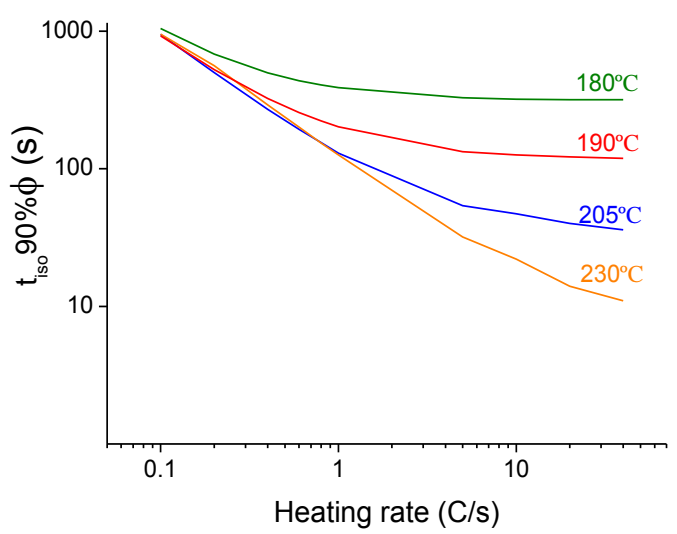

Figure 10 Isothermal annealing time required to achieve a 90\% accuracy of the correlation length growth exponent, $\phi$, when the initial correlation length is not considered. The calculation is performed for four different temperatures and for a range of heating rates from 0.1 to $40{ }^{\circ} \mathrm{C} / \mathrm{s}$ during the non-isothermal annealing. The correlation length was estimated using the model described in the article that takes into account the equivalent time, teq. Time equal to zero corresponds to the starting time of the isothermal annealing. All the samples were heated up from $150{ }^{\circ} \mathrm{C}$ to the target temperature $\left(180,205,215\right.$ and $\left.230^{\circ} \mathrm{C}\right)$ at different heating rates. The initial correlation length is set to $90 \mathrm{~nm}$ for all the curves.

\section{Conclusions}

The analysis of the kinetics of the structural order in lamellar structures of block copolymer kinetics using GISAXS allows access to statistical information over relatively large areas as compared to standard microscopy techniques. GISAXS characterization presents the additional advantage to be 
compatible with the self-assembly annealing experimental conditions usually employed in DSA processing, allowing for the in-situ and real time characterization of block copolymer ordering.

However, for data interpretation and, in order to take into account non-ideal experimental conditions, the classical modelling for BCP kinetics needs to be adapted. We have introduced a new parameter, the equivalent time, that enables the analysis of the evolution of the correlation length independently of the previous thermal history of the sample, caused for example by solvent evaporation or slow heating ramps. This approach can be used to reproduce the evolution of the correlation length on nonisothermal annealing. The model has been validated during different heating ramps but could be applied to any system where the temporal dependence of temperature is known.

Finally, we have demonstrated that, in order to obtain an accurate estimation of the parameters that determine the block copolymer self-assembly kinetics, the equivalent time should be considered when analysing the experimental data from the real time experiments. This effect is particularly important for samples undergoing a slow heating rate or annealed at low temperature if accurate values of the kinetics parameters need to be obtained.

Acknowledgements GISAXS experiments were performed at NCD-SWEET beamline at ALBA Synchrotron with the collaboration of ALBA staff. This project has received funding from the European Union's Horizon 2020 research and innovation programme under the Marie SkłodowskaCurie grant agreement No 665919, the Spanish Ministry of Economy and Competitiveness (MINECO) under Contract Nos. MAT2015-68307-P, MAT2015-66443-C02-1-R, TEC2015-69864-R, RTI2018-102007-B-I00, RYC-2016-21412 and, the Generalitat de Catalunya under contract 2017 SGR 1187. The ICN2 is funded by the CERCA program/Generalitat de Catalunya. The ICN2 is supported by the Severo Ochoa Centres of Excellence programme, funded by the Spanish Research Agency (AEI, grant No. SEV-2017-0706). (MINECO/FEDER, UE)

\section{References}

Ahn, H., Ryu, D. Y., Kim, Y., Kwon, K. W., Lee, J. \& Cho, J. (2009). Macromolecules. 42, $7897-$ 7902.

Bates, C. M., Maher, M. J., Janes, D. W., Ellison, C. J. \& Willson, C. G. (2014). Macromolecules. 47, $2-12$.

Bates, F. (1990). Annu. Rev. Phys. Chem. 41, 525-557.

Berezkin, A. V., Jung, F., Posselt, D., Smilgies, D. M. \& Papadakis, C. M. (2018). Adv. Funct. Mater. 28, $1-15$.

Berry, B. C., Bosse, A. W., Douglas, J. F., Jones, R. L. \& Karim, A. (2007). Nano Lett. 7, 2789-2794.

Black, C. T., Forrey, C. \& Yager, K. G. (2017). Soft Matter. 13, 3275-3283.

Chandra, A., Nakatani, R., Uchiyama, T., Seino, Y., Sato, H., Kasahara, Y., Azuma, T. \& Hayakawa, 
T. (2019). Adv. Mater. Interfaces. 6, 1-7.

Claveau, G. (2018). Etude d'une lithographie ligne/espace innovante par auto-assemblage dirigé d'un copolymère à blocs pour la réalisation de dispositifs CMOS sub-20nm. Université Grenoble Alpes.

Deal, B. E. \& Grove, A. S. (1965). J. Appl. Phys. 36, 3770-3778.

Di, Z., Posselt, D., Smilgies, D. M. \& Papadakis, C. M. (2010). Macromolecules. 43, 418-427.

Evangelio, L., Fernández-Regúlez, M., Fraxedas, J., Müller, M. \& Pérez-Murano, F. (2019). ACS Appl. Mater. Interfaces. 11, 3571-3581.

Fernandez-Regulez, M., Evangelio, L., Lorenzoni, M., Fraxedas, J. \& Perez-Murano, F. (2014). ACS Appl. Mater. Interfaces. 6, 21596-21602.

Ferrarese Lupi, F., Giammaria, T. J., Ceresoli, M., Seguini, G., Sparnacci, K., Antonioli, D., Gianotti, V., Laus, M. \& Perego, M. (2013). Nanotechnology. 24, 1-14.

Ferrarese Lupi, F., Giammaria, T. J., Seguini, G., Laus, M., Dubček, P., Pivac, B., Bernstorff, S. \& Perego, M. (2017). ACS Appl. Mater. Interfaces. 9, 11054-11063.

Förster, S., Timmann, A., Konrad, M., Schellbach, C., Meyer, A., Funari, S. S., Mulvaney, P. \& Knott, R. (2005). J. Phys. Chem. B. 109, 1347-1360.

Gottlieb, S., Kazazis, D., Mochi, I., Evangelio, L., Fernández-Regúlez, M., Ekinci, Y. \& PerezMurano, F. (2018). Soft Matter. 14, 6799-6808.

Gottlieb, S., Lorenzoni, M., Evangelio, L., Fernández-Regúlez, M., Ryu, Y. K., Rawlings, C., Spieser, M., Knoll, A. W. \& Perez-Murano, F. (2017). Nanotechnology. 28, 175301.

Gottlieb, S., Rösner, B., Evangelio, L., Fernández-Regúlez, M., Nogales, A., García-Gutiérrez, M. C., Keller, T. F., Fraxedas, J., Ezquerra, T. A., David, C. \& Perez-Murano, F. (2018). Mol. Syst. Des. Eng. 175-185.

Gu, X., Gunkel, I., Hexemer, A., Gu, W. \& Russell, T. P. (2014). Adv. Mater. 26, 273-281.

Hahm, J. \& Sibener, S. J. (2001). J. Chem. Phys. 114, 4730-4740.

Harrison, C., Adamson, D. H., Cheng, Z., Sebastian, J. M., Sethuraman, S., Huse, D. A., Register, R. A. \& Chaikin, P. M. (2000). Science (80-. ). 290, 1558-1560.

Harrison, C., Angelescu, D. E., Trawick, M., Cheng, Z., Huse, D. A., Chaikin, P. M., Vega, D. A., Sebastian, J. M., Register, R. A. \& Adamson, D. H. (2004). Europhys. Lett. 67, 800-806. Harrison, C., Chaikin, P. M., Huse, D. a., Register, R. a., Adamson, D. H., Daniel, A., Huang, E., Mansky, P., Russell, T. P., Hawker, C. J., Egolf, D. a., Melnikov, I. V. \& Bodenschatz, E. (2000). Macromolecules. 33, 857-865.

Harrison, C., Cheng, Z., Sethuraman, S., Huse, D. A., Chaikin, P. M., Vega, D. A., Sebastian, J. M., Register, R. A. \& Adamson, D. H. (2002). Phys. Rev. E - Stat. Physics, Plasmas, Fluids, Relat. Interdiscip. Top. 66, 1-27.

Hu, H., Gopinadhan, M. \& Osuji, C. O. (2014). Soft Matter. 10, 3867-3889.

IRDS (2018). International Roadmap for Devices and Systems (IRDS ${ }^{\mathrm{TM}}$ ) 2018 Edition. 
Jeong, S. J., Kim, J. Y., Kim, B. H., Moon, H. S. \& Kim, S. O. (2013). Mater. Today. 16, 468-476. Ji, S., Liu, C. C., Liao, W., Fenske, A. L., Craig, G. S. W. \& Nealey, P. F. (2011). Macromolecules. 44, 4291-4300.

Jung, Y. S. \& Ross, C. A. (2009). Adv. Mater. 21, 2540-2545.

Kim, B., Laachi, N., Delaney, K. T., Carilli, M., Kramer, E. J. \& Fredrickson, G. H. (2014). J. Appl. Polym. Sci. 131, 40790.

Lee, S., Cheng, L. C., Yager, K. G., Mumtaz, M., Aissou, K. \& Ross, C. A. (2019). Macromolecules. 52, 1853-1863.

Li, W. \& Müller, M. (2016). Prog. Polym. Sci. 54-55, 47-75.

Lorenzoni, M., Evangelio, L., Fernández-Regúlez, M., Nicolet, C., Navarro, C. \& Pérez-Murano, F. (2017). J. Phys. Chem. C. 121, 3078-3086.

Magerle, R. (2000). Phys. Rev. Lett. 85, 2749-2752.

Majewski, P. W. \& Yager, K. G. (2015). Soft Matter. 12, 281-294.

Marencic, A. P. \& Register, R. A. (2010). Annu. Rev. Chem. Biomol. Eng. 1, $277-297$.

Maret, M., Tiron, R., Chevalier, X., Gergaud, P., Gharbi, A., Lapeyre, C., Pradelles, J., Jousseaume, V., Fleury, G., Hadziioannou, G., Boudet, N. \& Navarro, C. (2014). Macromolecules. 47, 72217229.

Müller-Buschbaum, P. (2016). Eur. Polym. J. 81, 470-493.

Murphy, J. N., Harris, K. D. \& Buriak, J. M. (2015). PLoS One. 10, 1-32.

Papadakis, C. M., Di, Z., Posselt, D. \& Smilgies, D.-M. (2008). Langmuir. 24, 13815-13818.

Perego, M., Ferrarese Lupi, F., Ceresoli, M., Giammaria, T. J., Seguini, G., Enrico, E., Boarino, L., Antonioli, D., Gianotti, V., Sparnacci, K. \& Laus, M. (2014). J. Mater. Chem. C. 2, 6655-6664. Renaud, G., Lazzari, R. \& Leroy, F. (2009). Surf. Sci. Rep. 64, 255-380.

Rueda, D. R., Martín-Fabiani, I., Soccio, M., Alayo, N., Pérez-Murano, F., Rebollar, E., GarcíaGutiérrez, M. C., Castillejo, M. \& Ezquerra, T. A. (2012). J. Appl. Crystallogr. 45, 1038-1045. Samant, S., Strzalka, J., Yager, K. G., Kisslinger, K., Grolman, D., Basutkar, M., Salunke, N., Singh, G., Berry, B. \& Karim, A. (2016). Macromolecules. 49, 8633-8642.

Sanz, A., Rueda, D. R., Ezquerra, T. A. \& Nogales, A. (2011). J. Nanostructured Polym. Nanocomposites. 7, 10-17.

Segal-Peretz, T., Winterstein, J., Doxastakis, M., Ramírez-Hernández, A., Biswas, M., Ren, J., Suh, H. S., Darling, S. B., Liddle, J. A., Elam, J. W., De Pablo, J. J., Zaluzec, N. J. \& Nealey, P. F. (2015). ACS Nano. 9, 5333-5347.

Sepe, A., Hoppe, E. T., Jaksch, S., Magerl, D., Zhong, Q., Perlich, J., Posselt, D., Smilgies, D. M. \& Papadakis, C. M. (2011). J. Phys. Condens. Matter. 23, 254213.

Sinturel, C., Grosso, D., Boudot, M., Amenitsch, H., Hillmyer, M. A., Pineau, A. \& Vayer, M. (2014). ACS Appl. Mater. Interfaces. 6, 12146-12152.

Smilgies, D. M. (2009). J. Appl. Crystallogr. 42, 1030-1034. 
Soccio, M., Alayo, N., Martín-Fabiani, I., Rueda, D. R., García-Gutiérrez, M. C., Rebollar, E., Martínez-Tong, D. E., Pérez-Murano, F. \& Ezquerra, T. A. (2014). J. Appl. Crystallogr. 47, 613-618.

Tseng, Y. C. \& Darling, S. B. (2010). Polymers (Basel). 2, 470-489.

Yager, K. G., Fredin, N. J., Zhang, X., Berry, B. C., Karim, A. \& Jones, R. L. (2009). Soft Matter. 6, 92-99.

Zhang, J., Posselt, D., Smilgies, D.-M., Perlich, J., Kyriakos, K., Jaksch, S. \& Papadakis, C. M. (2014). Macromolecules. 47, 5711-5718. 
Supporting information

\section{S1. Evaluation of beam damage on Block copolymer samples}

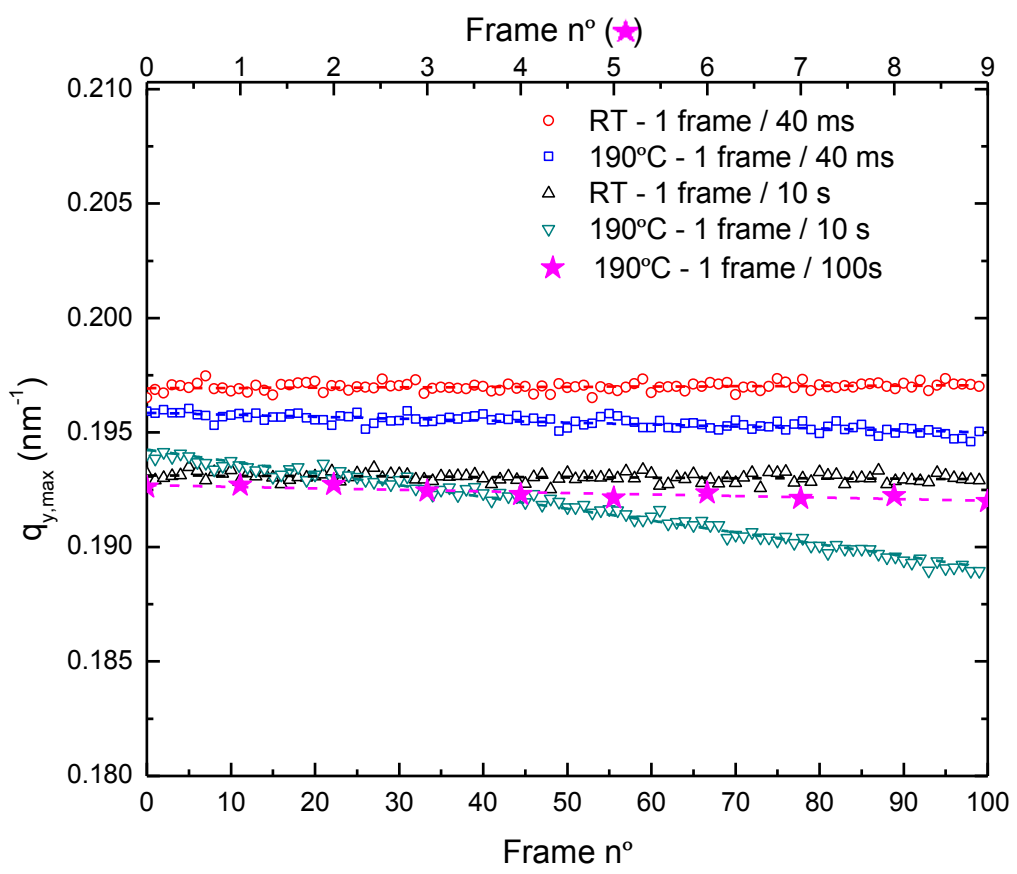

Figure S1 Effect of the GISAXS beam on the block copolymer sample at room temperature (RT) and at $190^{\circ} \mathrm{C}$. Evolution of Yoneda main peak position $\left(\mathrm{q}_{\mathrm{y}, \max }\right)$ at five different acquisition conditions. In the first fourth samples, 100 frames were taken using first $40 \mathrm{~ms}$ of exposure time (blue and red circles) and using 10s of exposure time (black and green triangles).As expected longer acquisition times and higher temperature caused more damage on the sample. In the last experiment, the sample was heated at $190^{\circ} \mathrm{C}$ and 10 frames with an acquisition time and period of $1 \mathrm{~s}$ and 100s were taken. The annealing time and temperature of this sample is similar than previous sample but the observed beam damage was minimal. 


\section{S2. Evolution of GISAXS patterns during isothermal annealing at different temperatures}
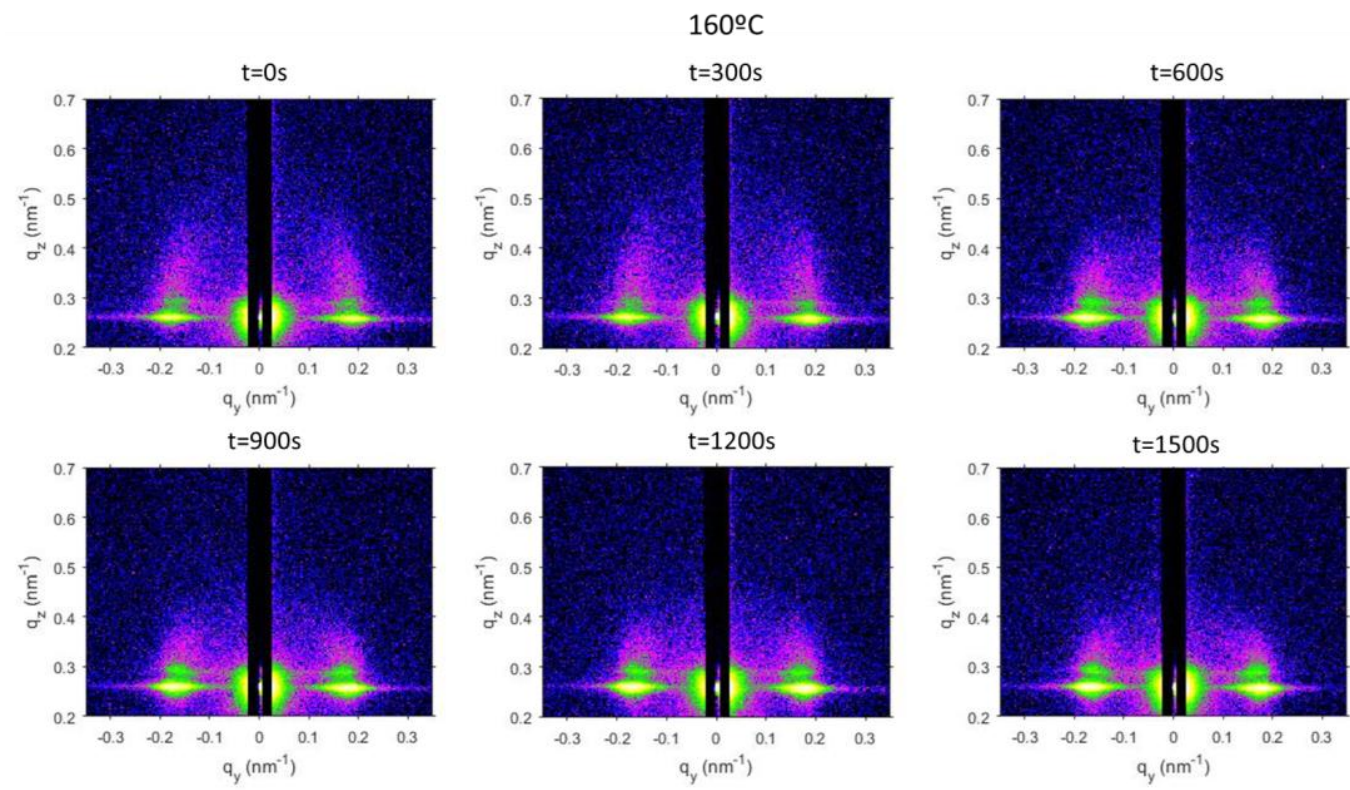

Figure S2 Selection of GISAXS patterns at different processing times during the thermal annealing at $160^{\circ} \mathrm{C}$. After reaching $160{ }^{\circ} \mathrm{C}(\mathrm{t}=0 \mathrm{~s})$ with a ramp rate of $50{ }^{\circ} \mathrm{C} / \mathrm{min}$, GISAXS patterns were collected with a frame rate of 1 frame of 0.037 s every $300 \mathrm{~s}$.
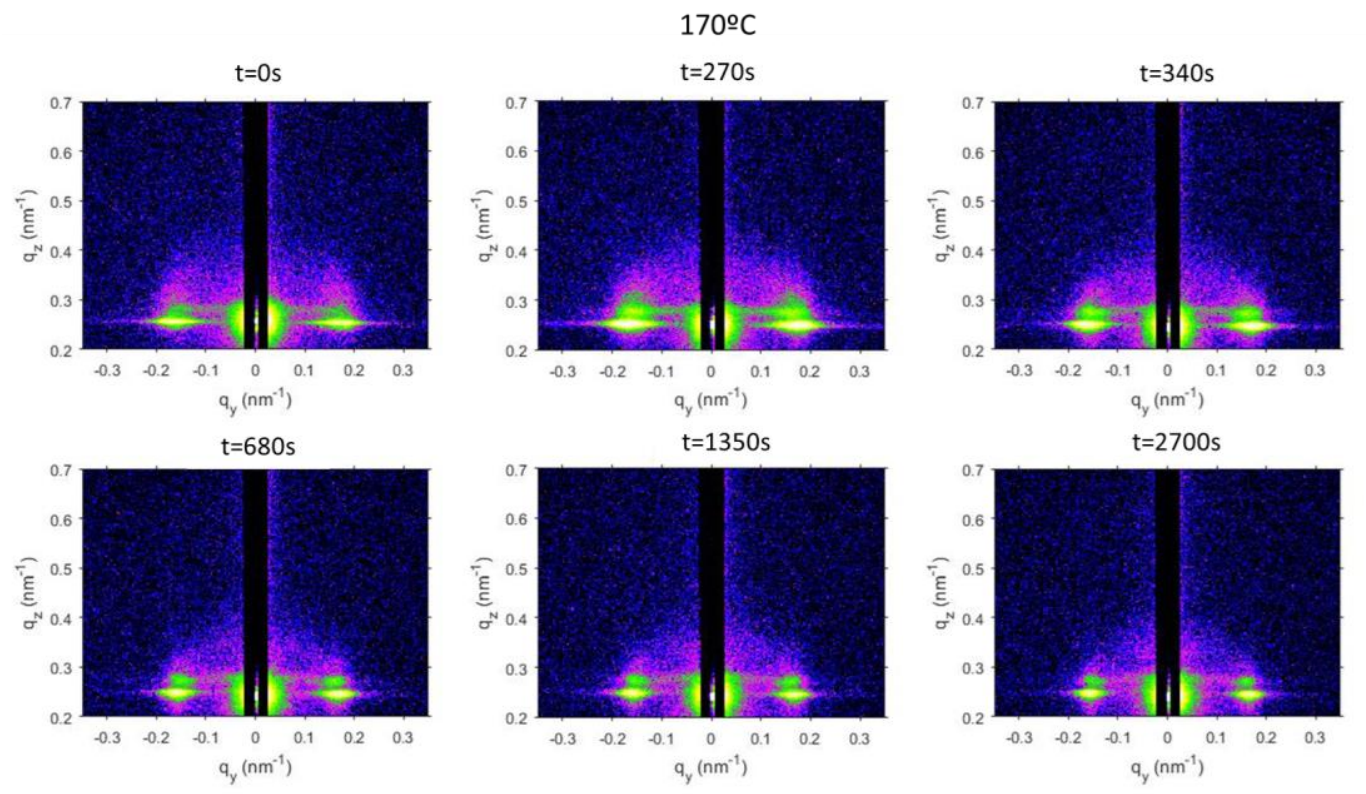

Figure S3 Selection of GISAXS patterns at different processing times during the thermal annealing at $170{ }^{\circ} \mathrm{C}$. After reaching $170{ }^{\circ} \mathrm{C}(\mathrm{t}=0 \mathrm{~s})$ with a ramp rate of $50{ }^{\circ} \mathrm{C} / \mathrm{min}$, GISAXS patterns were collected with a frame rate of 1 frame of $0.037 \mathrm{~s}$ every $135 \mathrm{~s}$. 

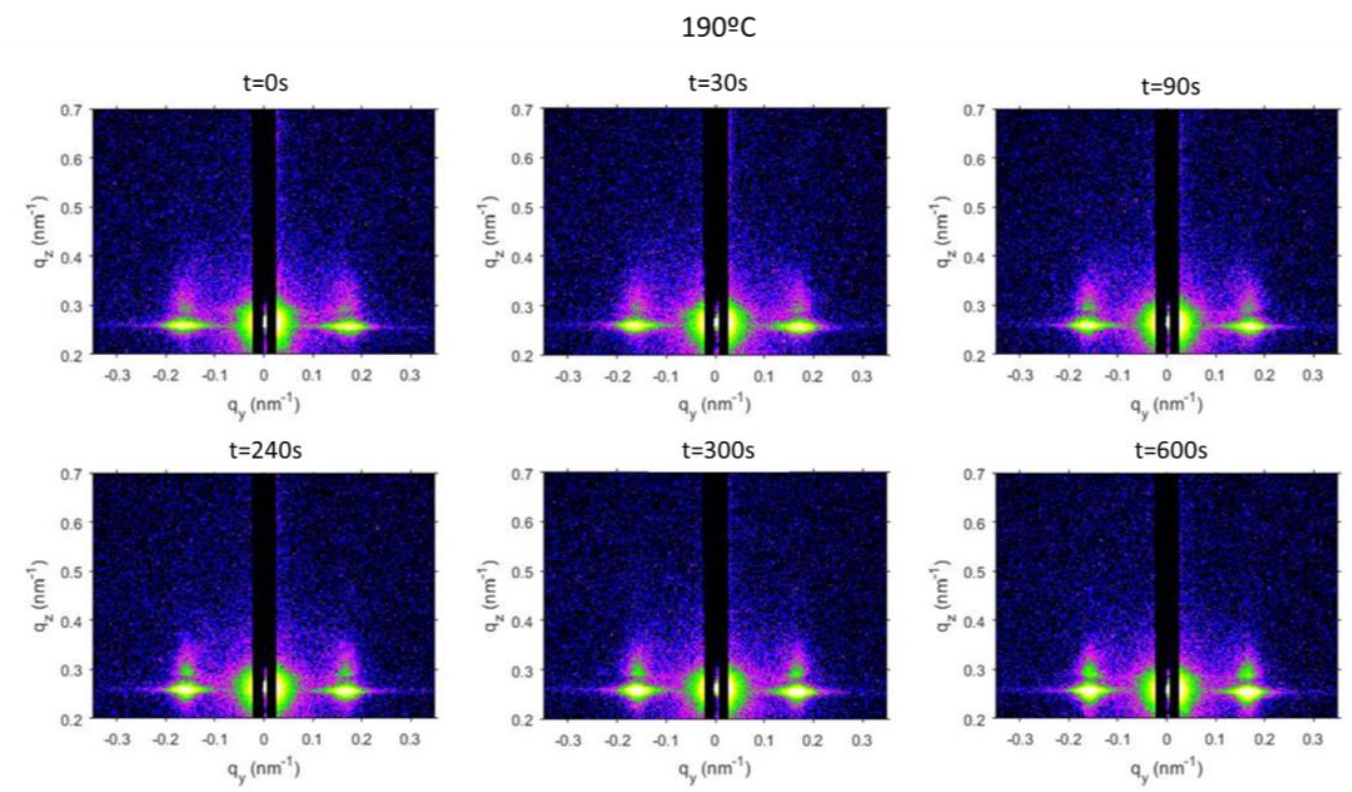

Figure S4 Selection of GISAXS patterns at different processing times during the thermal annealing at $190{ }^{\circ} \mathrm{C}$. After reaching $190{ }^{\circ} \mathrm{C}(\mathrm{t}=0 \mathrm{~s})$ with a ramp rate of $50^{\circ} \mathrm{C} / \mathrm{min}$, GISAXS patterns were collected with a frame rate of 1 frame of $0.037 \mathrm{~s}$ every $30 \mathrm{~s}$. 

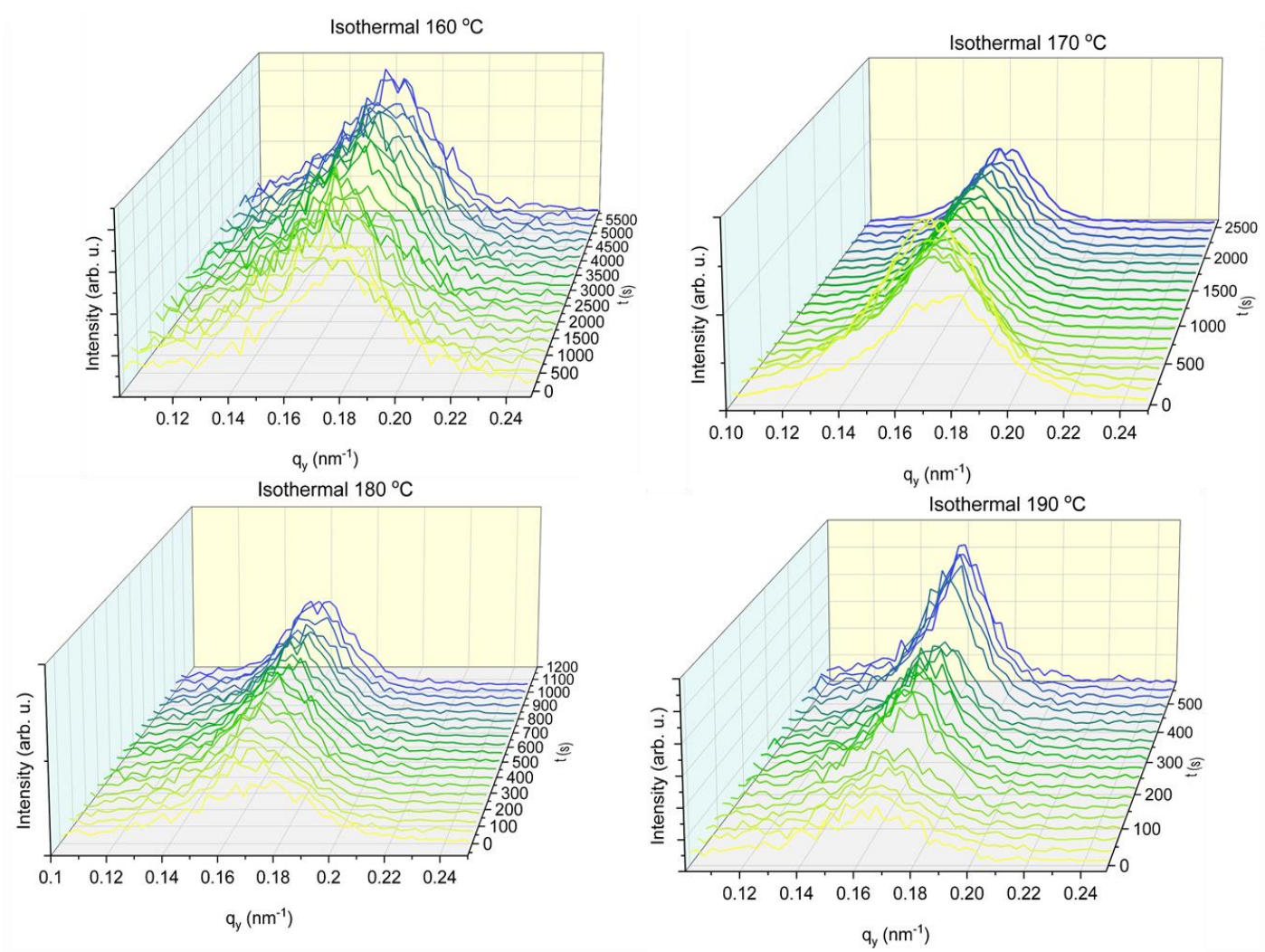

Figure S5 Detailed view of evolution with annealing time of the horizontal line cut at the first order scattering peak at Yoneda position. The profiles are extracted from the colour maps in Figure 4 (main text). The increase of the peak intensity and a reduction of the peak broadness during the thermal annealing arise from an increase of the long range order of the block copolymer pattern. 


\section{S3. Block copolymer evolution at low temperatures}
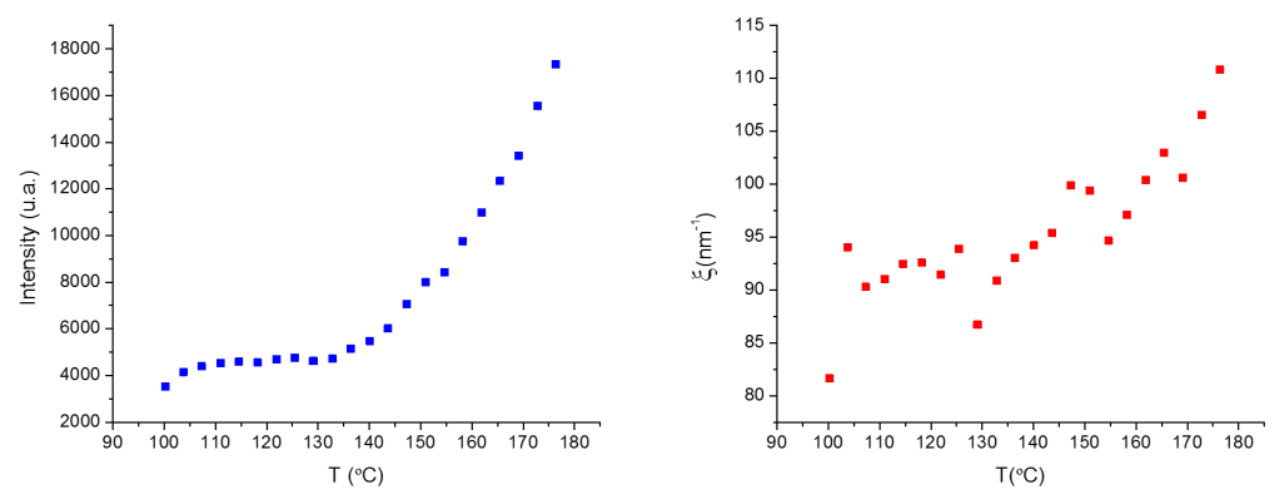

Figure S6 Intensity and correlation length of the first order peak at Yoneda band plotted as a function of the temperature. The experimental values were taken from GISAXS patterns during a heating ramp at $5^{\circ} \mathrm{C} / \mathrm{min}$. At low temperatures, up to $145^{\circ} \mathrm{C}$, there is not evolution on the block copolymer film, both intensity and correlation length remain constant. The initial order at lower temperatures is attributed to solvent evaporation during the spin-coating and at the beginning of the annealing process. 


\section{S4. Power exponent calculated using classical approach vs new model}
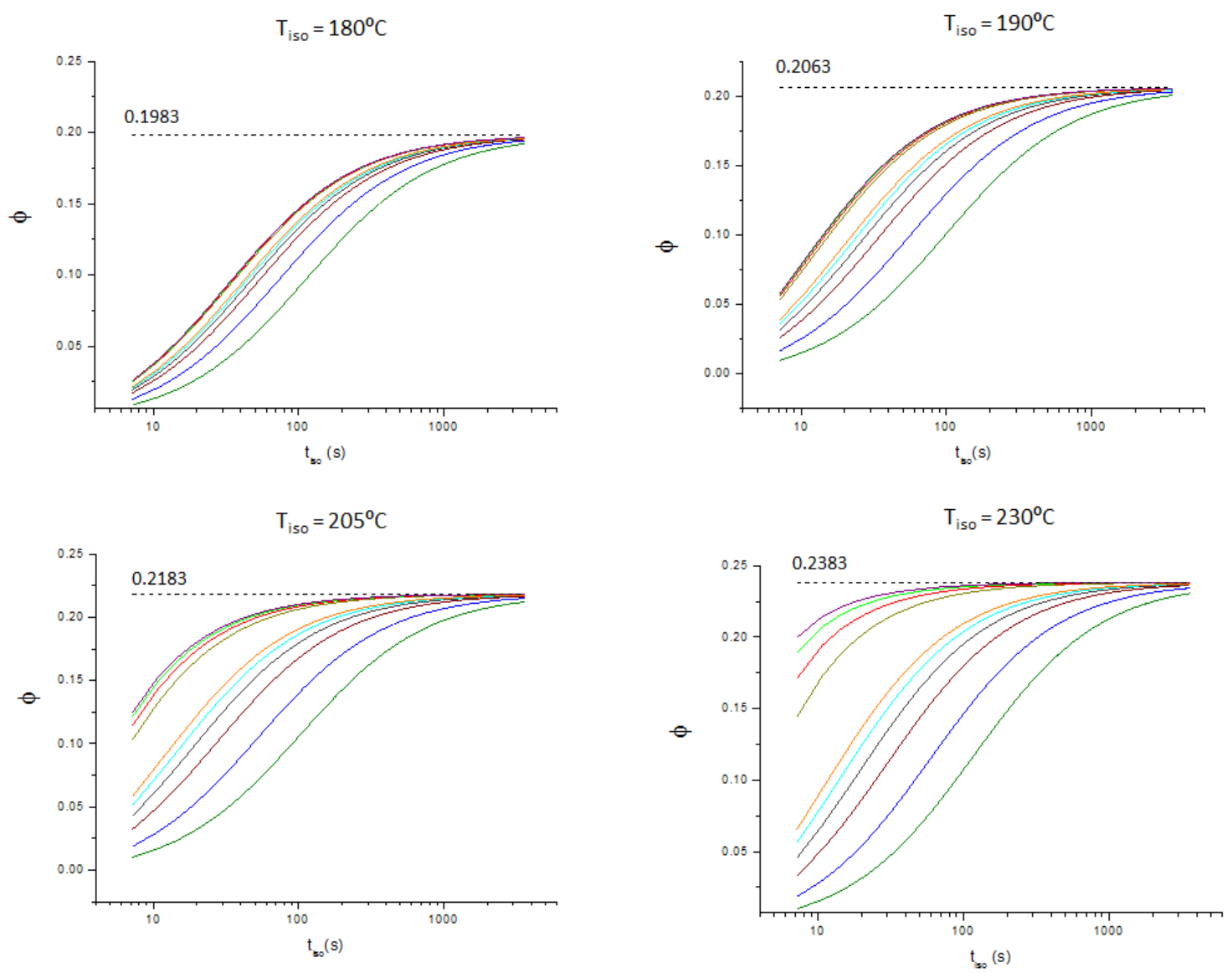

Figure S7 Power exponent, $\phi$, at different temperatures calculated from simulated curves using the classical approach, $\xi=A_{T} t^{\phi}$, from the slop of the curve $\log \xi$ vs $\log t$. The value of the power exponent calculated taking into account the equivalent time, $\xi=A_{T}\left(t+t_{e q}\right)^{\phi}$, is represented by a dashed line on each graph. Before isothermal annealing, the samples are annealed from $150^{\circ} \mathrm{C}$ to the target temperature, $T_{i s o}$, using a heating ramp of $1{ }^{\circ} \mathrm{C} / \mathrm{s}$ and a starting correlation length of $90 \mathrm{~nm}$. This demonstrate that only at long annealing times, the classical approach can be used for the calculation of the power exponent. 